ONTOGENESIS OF HEPATIC EPIDERMAL GROWTH FACTOR (EGF) METABOLISM IN NORMAL BALB MICE. Nilsa P. Laborde, Gertrudis G. Buenaflor, Pam I. Brown, Martin S. School of Medicine, Harbor-UCLA Medical Center, Department of Pediatrics, Torrance, CA.

To characterize the ontogenesis of the hepatic EGF system in normal Balb mice, we measured serum and liver concentrations of EGF, and liver concentrations of pre-pro EGF mRNA and EGF receptor binding. Male and female animals were studied at $1,2,3,5,7$ and 10 whs of life. After sacrifice, body weight and length were measured and serum and liver tissues were collected for EGF determinations. Immunoreactive serum EGF (mean \pm SEM) increased at 7 and 10 wks and was significantly higher $(p<0.05)$ in males ( $465 \pm$ 53 and $683 \pm 120 \mathrm{pg} / \mathrm{ml})$ than females $(188 \pm 52$ and $235 \pm 64 \mathrm{pg} / \mathrm{ml})$. Liver EGT concentrations were $10 \mathrm{w}$ at $1,2,3$ and 5 wks, significantly increasing $(p<0.01)$ at 10 wks to $268 \pm 50$ and $179 \pm 36 \mathrm{pg} / \mu \mathrm{g}$ protein for males ard females (males versus females $p<0.05$ at 10 wks). EGF receptor binding of 125 I-EGF was low at 1,2 and 3 wks increasing to $5.03 \pm 0.83$ and $5.79 \pm 1.02$ ( $\mathrm{fm} / \mu \mathrm{g}$ membrane protein) in males and $1.84 \pm 0.64$ and $2.36 \pm 0.28$ in females at 5 and 10 wks respectively. Values were significantly lower $(p<0.01)$ in females. Pre-pro EGF mRNA was examined at $1,2,3,5,7$ and 10 wks. EGF message increased in liver to highest values at 10 whs in both males and females. Conclusions: There is a parallel increase of serum and liver EGF concentrations, and liver EGF mRNA between 5 and 10 wks of postnatal life. EGF receptor binding also increases during this time. The results suggest that newborn liver may be an important source of circulating EGF in Balb mice.

\section{PAAPQACOKNNEIICS OF $T_{3}$ AND $T_{4}$ AFTER \\ ACUTE THYPOXENE OVERDOSE: EFFECT OF PTU AND \\ 453 IOPANIC ACID. Peter G. Lacouture, William J. Lewander, Enrique Silva, Frederick H. Iovejoy. Harvard Medical school, Children's Hospital, Dept. of Modicine, Boston, MA. over a 1 yr period, 15 ingestions of \\ thyrovine in children under 5 yrs of age were evaluated. All patients had initial serm $T_{4}$ levels determined within $7 \mathrm{hrs}$ of ingestion. valtiple $\mathrm{T}_{3}$ and $T$ serum levels were deternined in 7 patients. and $T$ serum levels were determined in 7 patients Peak $T$ levels ranged from 16-118 mog/dl with 3
patients $>75$ mog/dil. The estimated peak $T_{4}$ level occurred <12 hrs in $71 \%$ of the patients; the estimated peak $T_{3}$ level occurred $>20$ hrs in 718 of the \\ patients. In 5 patients who received no specific treatment, the mean serum $T_{4}$ tI/2 was 2.84 da (range 1.7-4.54 da) and the mean serum $T_{3}$ t1/2 was 5.1 da (range 1.9-12.3 da). Bpecific therapy to inhibit conversion of $T_{4}$ to $T_{3}$ was given in 2 patients furing which serum $t 1 / 2$ were:

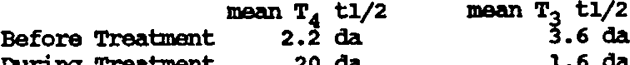

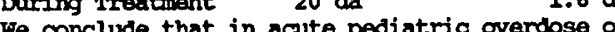 Wo conclude that in acute pediatric overilor thyrosine: (1) peak $T_{4}$ levels occur earlier than
peak $T_{3}$ levels, (2) in untreated patients the $t 1 / 2$ of poak $T_{3}$ levels, (2) in untreated patients the $T_{4}$ is shorter than $T_{3}$, and (3) shortly after $t 1 / 2$ and shorten $T_{3} t 1 / 2$.}

BONE DENSITOMETRY IN CONGENITAL ADRENAL HYPERPLASIA (CAH). Mary M. Lee,

454 Frances Ackland, Stephen Dahlem, Sidney Heyman, Thomas Moshang, Jr., Children's Hospital of Philadel Department of Pediatrics \& Radiology, Philadelphia, PA

Glucocorticoid therapy in $\mathrm{CAH}$ is titrated to maintain adequate adrenal suppression while avoiding the consequences of steroid excess. Although adrenal steroid levels may acutely reflect overdosage, chronic overtreatment is often suspected only after growth failure and retardation of bone age are noted. Osteoporosis is a failure and retardation of bon therapy and has been described in $\mathrm{CAH}$. Photon absorbtiometry is a simple, precise and noninvasive method of measuring bone demineralization. It may afford a more method of measuring bone demineatment than a bone age film, with sensitive measure of steroid overtreatment than a bone age film, with less radiation exposure. We measured bone density in 20 CAH patients ( 10 males and 10 females) using the linear radiation model levels as well as clinical aspects related to glucocorticoid treatment.

Preliminary data show that there is some correlation between bone density and glucocorticoid management of CAH. All the patients with elevated or borderline elevated adrenal steroid levels had bone density values in the normal range. 3 of 5 girls with biochemical values suggesting overdosage had bone density values in chemical values suggesting overdosage had bone density values in the range consistent with demineralization. None of these 3 had any
decline in growth velocity and bone ages done in 2 of the 3 showed no decline in growth velocity and bone ages done in 2 of the 3 showed no
delay. These preliminary data suggest that bone densitometry may delay. These preliminary data suggest that bone densitometry may in the earlier detection of oversuppression.
DEMONSTRATION OF DISRUPTED GONADOTROPIN FEEDBACK IN GONADAL FAILURE DURING CHILDHOOD BY LHRH ANALOGUE. 455 Perer A. Lee University of Pittsburgh School of Medicine, Children's Hospital of Pittsburg

Department of Pediatrics, Pittsburgh, PA 15213 .
The use of LHRH analogues as antagonists is well studied.Use of intermittent LHRH analogue (Lupron) as an agonist in the diagnosis or treatment of gonadal disorders is being investigated. To validate $1 \mathrm{ts}$ effect, $4 \mathrm{ug} / \mathrm{kg} / 2 \mathrm{X}$ week SQ injections were given to 8 males with delayed puberty. After one int greater the day after injection than the day before (LII $41.8 \pm 6.5$ vs $22.8 \pm 7.4, p<0.003$, FSH $63.5 \pm 9.0$ vs $40.9 \pm 11.9$, p < 0.011 ).

During chilthood, inappropriate gonadotropin secretion may not be apparent and the diagnosis of gonadal fallure may not be possible. The use of intermittent LHRH analogue as an agonist in stx six presties in 5 normal patients:

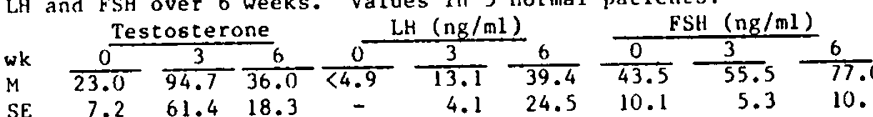
SE $\quad 7.2 \quad 61.4 \quad 18.3 \quad$ - $\quad 4.1 \quad 24.5 \quad 10.1$

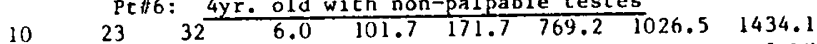

LHRH analogue stimulation resulted in an abnormal rise of LH and FSH without significant testosterone response. This demonstrates an abnormal feedback mechanism in childhood. This procedure may be a useful diagnostic test for evidence of gonadal fallure in children.

GROWTH HORMONE DEFICIENCY IN CIIILDREN WITH PRECOCIOUS PUBERTY: TREATMENT WITH AN LHRH ANALOGUE

456 Tsu-liui Lin and John L. Kirkland, Baylor College of

Sex steroid hormones can accelerate linear growth in children with growth hormone (GH) deficiency (GHD) without GH therapy. Therefore, GHD may not be suspected in children who are in puberty. LHRH analogue (LHRHa) therapy in children with precocious puberty (PP) has been demonstrated to decelerate the rapid growth velocity associated with elevated sex steroid hormones. We report two children below with PP in whom GHD was diagnosed after their linear growth was decelerated by intranasal administratior of LHRHa (Nafarelin).

\begin{tabular}{|c|c|c|c|c|c|}
\hline Patient & $C A$ & BA & GRa & GRb & GRC \\
\hline 1 & $8 \overline{775}$ & $12 . \overline{75}$ & $\overline{7.2}$ & $\overline{1.5}$ & $\overline{5.0}$ \\
\hline 2 & 5.5 & 9.5 & 8.4 & 2.5 & 10.2 \\
\hline
\end{tabular}

$C A=$ chronological age in years; $B A=$ bone age in years; $G R=$ growth rate in cm/year: a=before LHRHa therapy, $b=$ during LHRHa therapy, $\mathrm{c}=$ combined LHRHa and $\mathrm{GH}$ therapy

GHD in children with PP may be more common than suspected previously. Recognition of this fact is important since a major complication of PP is short stature as an adult. The combination of GH and LHRHa therapy provided a more normal growth velocity for these children. These findings suggest that for some children with GHD, LHRHa therapy may be indicated to optimize their final adult height. (Supported by FD-R-000097 and USPH RR-00188) EFFECTS OF GROWTH HORMONE ON BONE DENSITY IN CHILDREN WITH TURNER SYNOROME. Tsu-HuI Lin, Rebecca 457 T. Kirkland, Adrian D. LeBlanc, Harlan Evans and John L. KIrkland, Baylor College of Medcine, Department of Pediatrics and Nuclear Medicine, Houston, TX.

Children with Turner syndrome (TS) frequently have asymtomatic osteoporosis by radiologic diagnosis. Growth hormone (GH) has been considered as a therapeutic or preventive measure for osteoporosis. $G H$ also has been demonstrated to be effective in improving growth velocity in children with TS. This study was designed to determine the changes in bone density associated with GH therapy.

Eight chlldren with TS $(45, X$ in $3 ; 45, X / 46 X, X q$ in $1 ; 45, X / 46$, $X, i \operatorname{dic}(X)$ in 1; 45,X/46,X,idic $(Y)$ in 1; 45,X/46X, $X X(p 1$ 1q22); and $45, X / 46 X$, iso $(X q)$ in 1$)$ were studied between chronological ages of 7 to 13 with bone ages of 3 to 11 years. The bone density changes were assessed by dual beam photon densitometry with a program modified for children. The area studled was L2-L4. Bone density was measured every 6 months. Each patient served as her own control for 6 months before GH therapy was started. GH was administered intramuscularly three times weekly at a dosage of $0.125 \mathrm{mg} / \mathrm{Kg} /$ dose. Changes in bone density at 6 months of control period was $0.020_{-}^{+} 1.975 \mathrm{gm} / \mathrm{cm}^{2} / \mathrm{yr}$ (mean_SEM). During six months of $\mathrm{GH}$ therapy changes in bone density was $0.007^{+} 0.021$ $\mathrm{gm} / \mathrm{cm}^{2} / \mathrm{yr}(P>0.05)$. This indicates a lack of effectiveness of $\mathrm{GH}$ therapy on bone density in children with TS. Further study is required to determine if this lack of effectiveness is because the children were growing or because children with TS may respond differently from the general population. 